\title{
Positive storm effects in the dayside polar ionospheric F-region observed by EISCAT and ESR during the magnetic storm of 15 May 1997
}

\author{
S. Y. Ma ${ }^{1}$, H. T. Cai ${ }^{1}$, H. X. Liu ${ }^{2}$, K. Schlegel ${ }^{3}$, and G. Lu $^{2}$ \\ ${ }^{1}$ Dept. of Space Physics, College of Electronic Information, Wuhan University, Wuhan 430072, P. R. China \\ ${ }^{2}$ High Altitude Observatory, National Center for Atmospheric Research, 3450 Mitchell Lane, Boulder, CO 80301, USA \\ ${ }^{3}$ Max-Planck-Institut für Aeronomie, D-37191 Katlenburg-Lindau, Germany
}

Received: 11 October 2001 - Revised: 22 April 2002 - Accepted: 14 May 2002

\begin{abstract}
EISCAT/ESR radar data and in situ FAST and POLAR satellite observations are coordinately analyzed to investigate positive ionospheric storm effects in the dayside upper F-region in both the polar cap and the auroral oval during the magnetic storm of 15 May 1997. An ionization enhancement, lasting for about $2.5 \mathrm{~h}$, appeared first over the EISCAT site around magnetic noon; about one hour later, a similar ionization enhancement was also seen over ESR. During the concerned time period ion energy spectra measured on board FAST show clearly continuous energy-latitude dispersion when the satellite passed by over the EISCAT latitude. This implies that EISCAT was located under the polar cusp region which was highly active, and expanded greatly equatorwards due to magnetopause reconnections during longlasting southward IMF. Simultaneously, soft particles of the magnetosheath precipitated into the F-region ionosphere and caused the positive storm effects over EISCAT. The coincident increase in electron temperature at EISCAT gives additional evidence for soft particle precipitation. Consistently, POLAR UV images show strong dayside aurora extending to as low as $62^{\circ} \mathrm{N}$ magnetic latitude. The ionization enhancement over ESR, however, seems not to be caused by local particle precipitation, evidenced by a lack of enhanced electron temperature. The observed plasma convection velocity and data-fitted convection patterns by AMIE suggested that it is likely to be a polar patch originating from the cusp region and traveling to the ESR site.
\end{abstract}

Key words. Ionosphere (auroral ionosphere; particle percipitation). Magnetospheric physics (storms and substorms)

\section{Introduction}

Ionization enhancements in the ionospheric F-region responding to magnetic storms are usually called positive ionospheric storms. Morphology and physical mechanisms of

Correspondence to: S. Y. Ma (syma@whu.edu.cn) positive ionospheric storms at mid- and low-latitudes have been investigated extensively in recent decades (e.g. Rishbeth et al., 1987; Fuller-Rowell et al., 1990, 1994; Danilov \& Berlik, 1992; Prölss, 1995; Mikhailov et al., 1995; Namgaladze et al., 2000; and references therein). The physics for this phenomenon involves F-region uplifting towards lower recombination loss regions by an enhanced equatorward neutral wind excited in the heated auroral region, the thermospheric composition changes of $\mathrm{O} / \mathrm{N}_{2}$, and the electric field caused by the disturbance dynamo effect, etc. In contrast, positive storm effects in the polar F-region are often associated with an impact of soft particles precipitating from magnetospheric source regions. For the magnetic noon sector of the auroral oval, the particles precipitate from four distinct regions: (i) the magnetosheath through active cusp, (ii) the plasma-mantle through the region poleward of the cusp, (iii) the low-latitude boundary layer between the dawn and evening flanks through the so-called cleft, and (iv) the dayside boundary plasma sheet (Newell and Meng, 1988, 1989; Newell et al., 1991; Kennel, 1995; Lyons et al., 1999). Of them, the relation of positive polar ionospheric storm and active cusp is quite acute and has received the attention of scientists for a long time (e.g. Danilov et al., 1987; Danilov, 2001).

On the other hand, it is evident that enhancements in the electron density of the ionospheric F-region created by cusp/cleft particle precipitation at the dayside entry to the polar-cap convection flow play an important role in the formation of polar-cap patches (e.g. Valladares et al., 1994; Walker et al., 1999; Smith, et al., 2000). Most of these observations, however, are not related to magnetic storms. During the magnetic storm of 15 May 1997, both the EISCAT radar (geog. lat. $69.6^{\circ} \mathrm{N}$, long. $19.2^{\circ} \mathrm{E}$ ) and the EISCATSvalbard radar (ESR, geog. lat. $78.0^{\circ} \mathrm{N}$, long. $16.0^{\circ} \mathrm{E}$ ) were in operation and caught the storm simultaneously during its main phase at the dayside sector. In our previous paper (Liu et al., 2000), it was indicated that, according to calculations by means of the T96-01 magnetic field model (Tsy- 

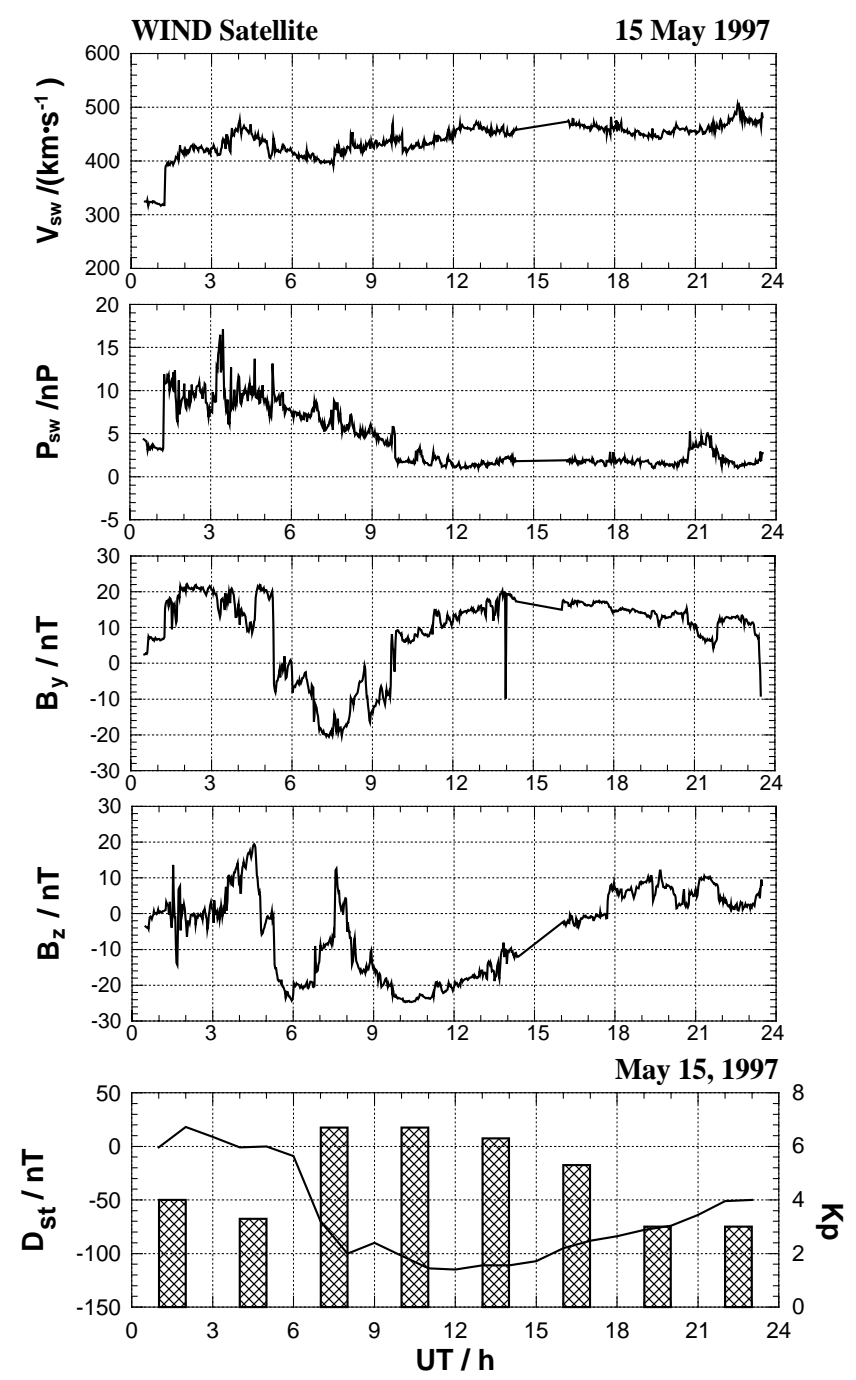

Fig. 1. (a) Solar wind speed, (b) Solar wind dynamical pressure, (c) IMF $B_{y}$, (d) IMF $B_{z}$, (e) Magnetic indices of $\mathrm{D}_{s t}$ and $K_{p}$. The solar wind and IMF parameters were recorded on the WIND satellite on 15 May 1997.

ganeko, 1996), ESR was in the dayside polar cap during the main phase and the beginning of the recovery phase of the 15 May 1997 storm, while EISCAT was in the dayside auroral oval or on its poleward boundary, being in agreement with the UV images taken from the ultraviolet imager (UVI) on board the POLAR satellite. This provides a valuable opportunity to investigate storm effects in the dayside auroral oval and in the polar cap regions simultaneously. A comparative study mainly on the negative storm effects observed by EISCAT and ESR radar during this storm has been made in our paper mentioned above. In this contribution, we will focus our attention on a dayside F-region positive storm superposed on the long-lasting negative phase of this storm.

\section{Observation results}

\subsection{Interplanetary conditions and geomagnetic indices}

Figure 1 shows solar wind and IMF data from the WIND spacecraft, together with the $\mathrm{D}_{s t}$ and $K_{p}$ indices for 15 May 1997. WIND observed the passage of an interplanetary shock at 01:16 UT, followed by several hours of high solar wind dynamic pressure. The IMF turned southward at 04:46 UT, indicating the arrival of the magnetic cloud at the WIND location (Cane et al., 1998). The IMF $B_{z}$ shows two minima, with the first of $-24.3 \mathrm{nT}$ at 05:56 UT and the second of $-24.7 \mathrm{nT}$ at 10:23 UT. The IMF $B_{z}$ experienced reversals from south to north, then back to south between the two minima. WIND was located at $X_{s e}=1.21 \times 10^{6} \mathrm{~km}$ at 12:00 UT and the $X$ component of the solar wind velocity $V_{x}$ was $-440 \mathrm{~km} / \mathrm{s}$, giving a travelling time of $43 \mathrm{~min}$ from the position of the WIND spacecraft to the subsolar magnetopause. The $\mathrm{D}_{s t}$ index rose slightly at 01:59 UT, indicating a storm sudden commencement (SSC) caused by the interplanetary shock at 01:16 UT (Cane et al., 1998). After being nearly constant for four hours, it decreased rapidly and reached a minimum of $-115 \mathrm{nT}$. Afterwards it recovered gradually to the normal level. The maximum $K_{p}$ value was $7^{-}$.

For the period around the maximum of the magnetic storm main phase that is concerned in this paper, the IMF $B_{z}$ remained less than $-20 \mathrm{nT}$, i.e. being very intense and directed southward; while the IMF $B_{y}$ underwent an excursion from about $-10 \mathrm{nT}$ to $20 \mathrm{nT}$. The solar wind dynamic pressure stayed at a low level of about $2-4 \mathrm{nPa}$.

\subsection{Positive storm observed by EISCAT}

Figure 2a shows a 2-D image of F-region electron density distribution versus UT and height at the EISCAT site during 06:00-13:00 UT. It can be clearly seen that a stable layer of ionization enhancement which peaked at about $350 \mathrm{~km}$ height appeared during 09:10-11:30 UT ( 11:0513:25 MLT, MLT $\approx \mathrm{UT}+1.9 \mathrm{~h}$ ) in the upper F-region. For comparison, Fig. $2 b$ gives a reference that is an average of available observations on some quiet days with maximum of $K_{p}$ less than 3 during April to June of 1997 . Figure 2c shows the percentage deviation of the electron density on 15 May with respect to the reference. Considering the possible dayto-day variations of $N_{e}$ at about $20 \%$ or more, only the stormtime deviations with magnitude larger than $20 \%$ are referred to as storm effects. Thus, it indicates that strong positive storm effects took place above $340 \mathrm{~km}$, lasting for about $2 \mathrm{~h}$ from 09:15-11:00 UT ( 11:10-12:55 MLT), superposed on a negative effect background. The maximum deviation is located above $450 \mathrm{~km}$ with a magnitude larger than $80 \%$.

The very strong, short ionization enhancement around 08:06 UT, which extended from the E-region to the high upper F-region, is probably a satellite echo. 

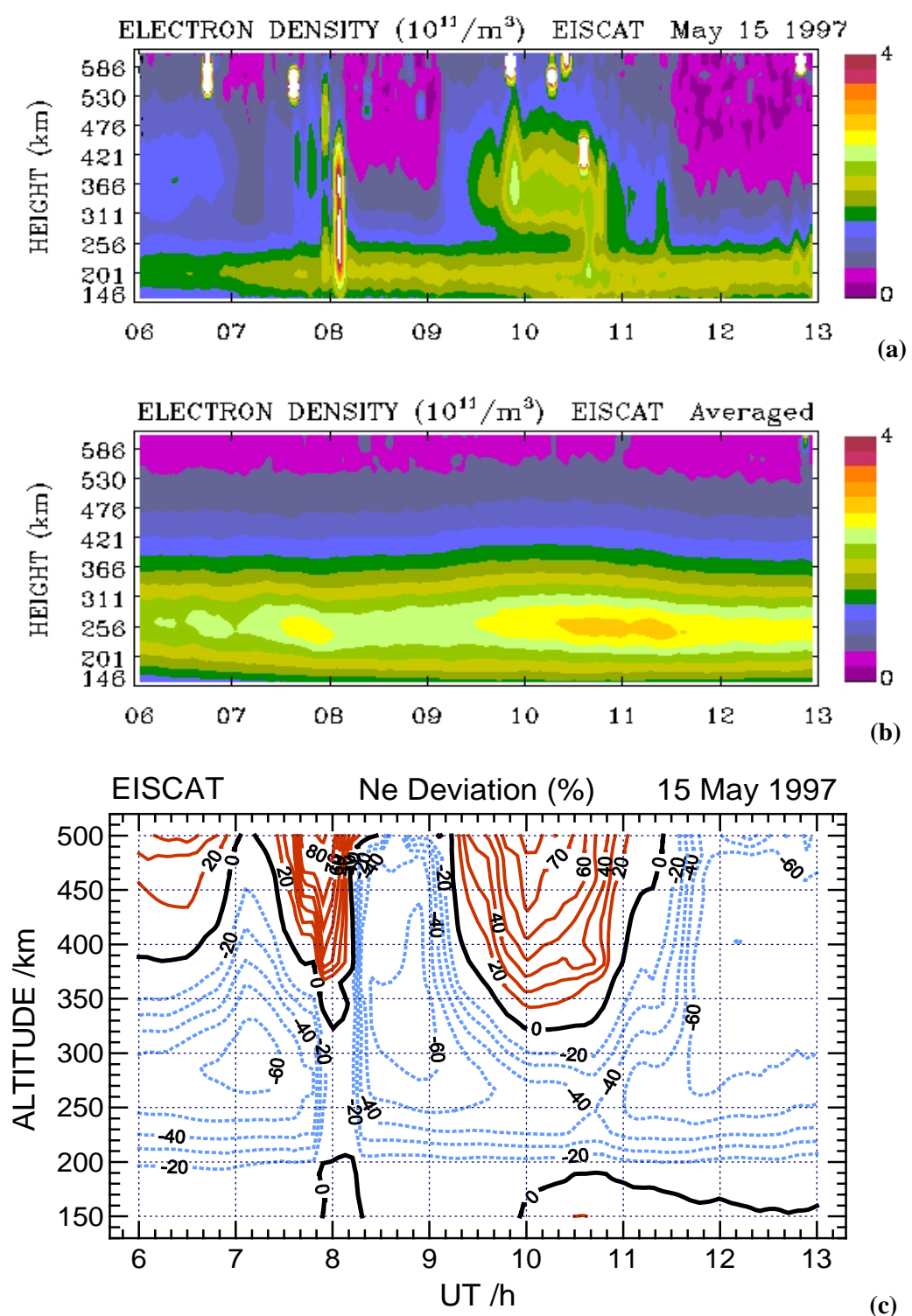

(c)

Fig. 2. (a) Two-dimensional image of electron density distribution vs. UT and height at the EISCAT site on 15 May 1997 , (b) the same as Fig. 2a but for a reference that is an average of the observations on some quiet days in April and June of 1997, (c) deviation of electron density during the magnetic storm of 15 May 1997 with respect to the quiet reference.

\subsection{Positive storm observed at ESR}

Figure 3a shows a 2-D distribution of electron density versus UT and height observed at the ESR site on 15 May 1997. It is seen that an ionization enhancement which peaked at about $380 \mathrm{~km}$ height appeared during 10:20-11:15 UT in the upper F-region. In comparison with the one observed at the EISCAT site, the peak height was about $40 \mathrm{~km}$ higher. Figure $3 b$ gives a reference that is an average of the available observations on some quiet days, with maximum of $K_{p}$ less than 3 during April to June of 1997. Figure 3c represents the percentage deviation of electron density on 15 May with respect to the reference. It shows that strong positive storm effects took place above $370 \mathrm{~km}$, between 10:20-11:30 UT, superposed on a negative effect background. The deviation is peaked at $380 \mathrm{~km}$ and above $470 \mathrm{~km}$ with a magnitude of larger than 50\%. In comparison with the observations at the EISCAT site, the positive storm effects seem weaker, and appeared one hour later, lasting about one hour shorter. Besides, we can see from Fig. 3a that F-region ionization enhancements also occurred around 09:10 UT and 09:50 UT. They were superposed on a negative storm phase, showing no obvious increase in electron density in comparison with the reference (see Fig. 3c). Simultaneous measurements of $N_{e}$ and $T_{e}$ during the time periods mentioned above indicated (shown later in Sect. III) that they were associated with local soft particle precipitation. These enhancements of electron densities will not be regarded much in this paper, while we 

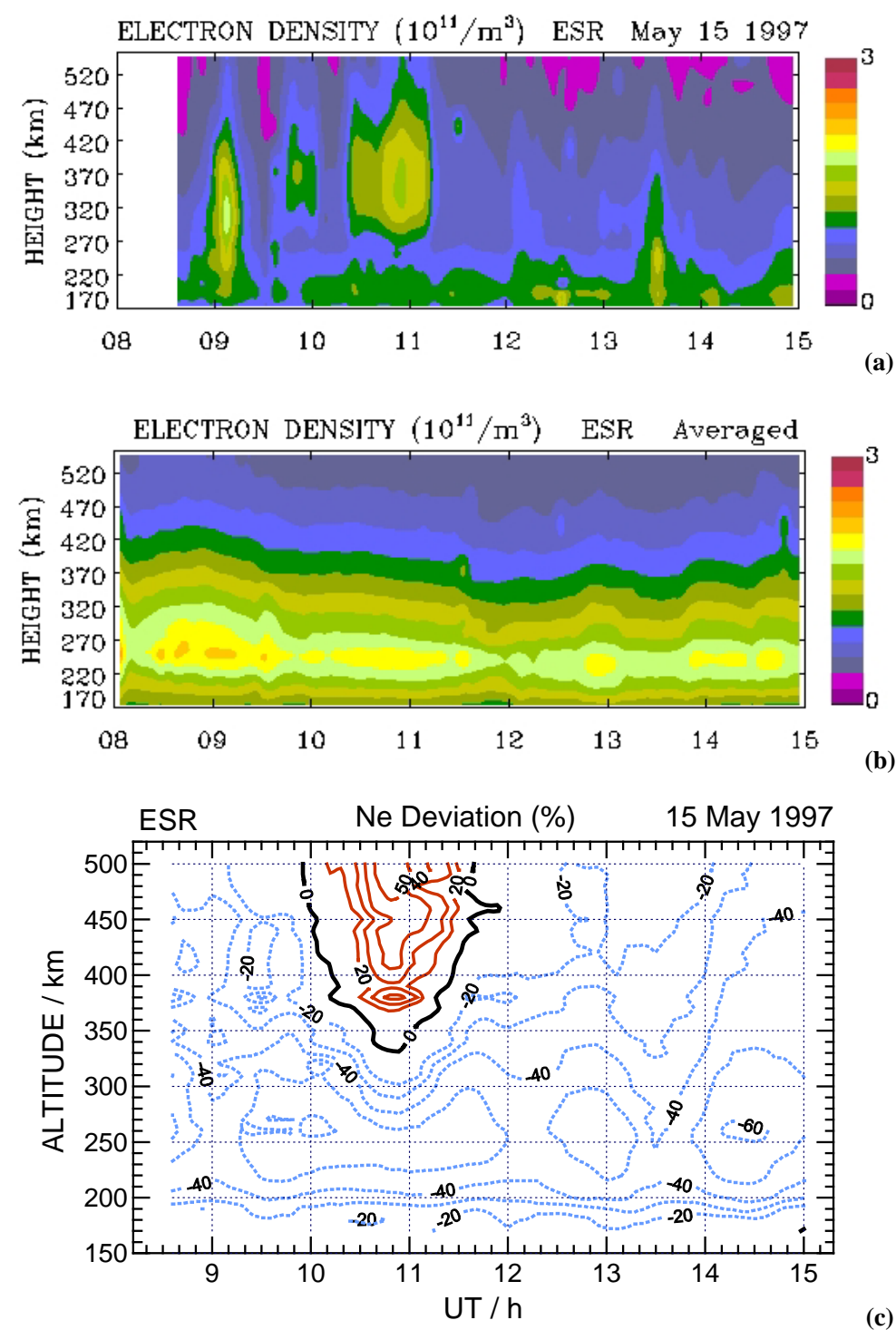

(b)

(c)

Fig. 3. (a) Two-dimensional image of electron density distribution vs. UT and height at ESR, (b) the same as Fig. 2a but for a reference that is an average of the observations on some quiet days in April and June of 1997, (c) deviation of electron density during the magnetic storm of 15 May 1997 with respect to the quiet reference at ESR.

focus our attention on the positive storm appearing between 10:20-11:30 UT.

\section{Discussion}

3.1 Particle precipitation as a source of the dayside positive storm at EISCAT

\subsubsection{Evidence of association with local soft electron pre- cipitation}

Figure 4 shows time variations of electron density $N_{e}$ and temperature $T_{e}$ at $344 \mathrm{~km}$ height observed with the EISCAT radar during the concerned positive storm phase. We can see that $N_{e}$ and $T_{e}$ coincidently increased at 09:06 UT, jumping rapidly from $0.57 \times 10^{11}$ to $1.23 \times 10^{11} \mathrm{el} . / \mathrm{m}^{3}$ for $N_{e}$ and from $1890 \mathrm{~K}$ to $2600 \mathrm{~K}$ for $T_{e}$, within $10 \mathrm{~min}$. At about 11:30 UT, both recovered to the original level. This implies that the considered upper F-region ionization enhancement at EISCAT is related to soft electron precipitation. According to simulation results of Millward et al. (1999), the energies of the precipitating electrons are probably centered at around a few hundred eV, suggesting magnetosheath-like particles.

\subsubsection{Association with the active cusp}

To confirm that EISCAT was indeed under the cusp region during the concerned time period, particle measurements from the FAST satellite are examined. Between 09:4109:56 UT, FAST passed over the northern polar region and 


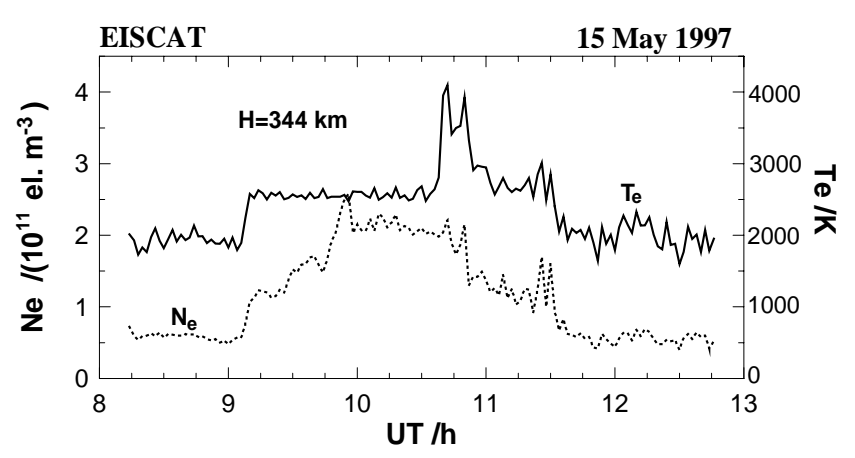

Fig. 4. $N_{e}$ and $T_{e}$ versus UT at $344 \mathrm{~km}$ height observed with the EISCAT radar.

took a snapshot of energetic particles at heights of 380$1340 \mathrm{~km}$ over the auroral and the polar cap region. In particular, the Time-of-Flight Energy Angle Mass Spectrograph recorded a characteristic ion energy-latitude dispersion of cusp precipitating particles (Shelley et al., 1976; Reiff et al., 1977; Lockwood and Smith, 1994) between 09:41:3809:43:40 UT, as shown in Fig. 5. The main ion composition of the precipitation is $\mathrm{H}^{+}$, with energies dispersing from about $10 \mathrm{keV}$ to $30 \mathrm{eV}$ (see top panel of Fig. 5); the energies of precipitating electrons range from $50 \mathrm{eV}$ to $1000 \mathrm{eV}$ (not given here). Ions with higher energy are observed first at lower latitudes. With poleward convection of newly opened force lines, ions with lower energy are then seen at higher latitudes. Within this time interval FAST orbited at 401$470 \mathrm{~km}$, the geographic latitude of the force line foot-point tracing to FAST ranged from $68.3^{\circ}$ to $75.9^{\circ} \mathrm{N}$, and the local time was between 13:35 and 14:20 LT. It is obvious that the satellite trajectory covered the latitude of the EISCAT site at the equatorward edge of the ion dispersion region. It is evident, therefore, that EISCAT was continually under the cusp region during the concerned interval, and the F-region positive storm effects around magnetic noon can be attributed to clef/cusp/plasma-mantle precipitation due to continuous reconnection at the dayside magnetopause. An exact determination of the specified particle precipitation region is not easy due to a lack of necessary particle data over the EISCAT site.

\subsubsection{Evidence of strong dayside aurora near EISCAT by POLAR UVI}

An UV image of aurora observed on the POLAR satellite at 09:52 UT (see Fig. 6) gives another evidence that during the considered time interval, EISCAT was probably located under or adjacent to the cusp region, where strong dayside aurora appeared. Thus, the sources of positive storm effects in the upper F-region are likely to be the cleft/cusp/plasmamantle particle precipitation.

\subsection{Source of the positive storm at ESR}

Figure 7 shows the electron density and temperature observed by the ESR radar during 08:30 UT to 15:00 UT at $380 \mathrm{~km}$ height, where the maximum positive storm effect appeared. Since there is a data gap in $T_{e}$ at $380 \mathrm{~km}$, between 09:30-10:00 UT, the relevant variations of $N_{e}$ and $T_{e}$ at the adjacent height of $416 \mathrm{~km}$ are also given in this figure. We can see that enhancements in electron density around 09:10 UT and 09:50 UT are accompanied by a remarkable increase in electron temperature, suggesting their association with local soft particle precipitation. It has been shown in our previous paper (Liu et al., 2000) that these two electron enhancements are peak-to-peak correlated with a large pulselike increase in solar wind dynamic pressure by pressurecontrolled soft particle precipitation. On the other hand, there is no remarkable increase in electron temperature accompanying the "blob" between 10:40 UT to 11:10 UT. This means that local particle precipitation did not cause the concerned "blob". Long-lasting large ion upflow (Liu et al., 2000) may also be a possible evidence that the positive storm at ESR is probably not attributed to local particle precipitation. These facts lead us to transportation effects due to plasma convection flow and thermospheric circulation for the positive Fregion storm at ESR.

It is shown in Fig. 8 that the northward plasma convection over EISCAT during 09:20-10:20 UT exhibits an average speed of about $250 \mathrm{~m} / \mathrm{s}$. The east-west flow velocity of the enhanced plasma cloud travelling out from the EISCAT site around the merging gap region is expected to undergo complex changes due to IMF $B_{y}$ switching from dawnward to duskward. We checked the polar ionospheric convection patterns during 09:20-10:00 UT that were calculated by AMIE (Assimilative Mapping of Ionospheric Electrodynamics) of NCAR (Richmond, 1992). The patterns show that EISCAT was near the merging gap on the dusk convection cell, while ESR was within the polar cap on the same cell. Furthermore, two radar stations were located on the nearly equal or slightly different potential lines (i.e. on nearly the same convection line), as shown in Fig. 9. The speed along the convection line was at a level of about $200-600 \mathrm{~m} / \mathrm{s}$ by a rough estimate. Therefore, it is very likely that the high density plasma cloud created near EISCAT may travel toward and reach the ESR site in 1 to $1.5 \mathrm{~h}$, although an exact demonstration should be made of tracing the plasma parcel trajectory. So, we suppose that the upper ionospheric ionization enhancement observed by ESR is probably a travelling polar patch originated from around the cusp region and convected to the ESR site.

\section{Summary}

In this paper, EISCAT/ESR radar data and in situ FAST and POLAR satellite observations have coordinately been analyzed to investigate positive ionospheric storm effects in the dayside upper F-region in both the polar cap and the auroral oval during the magnetic storm of 15 May 1997. We found 

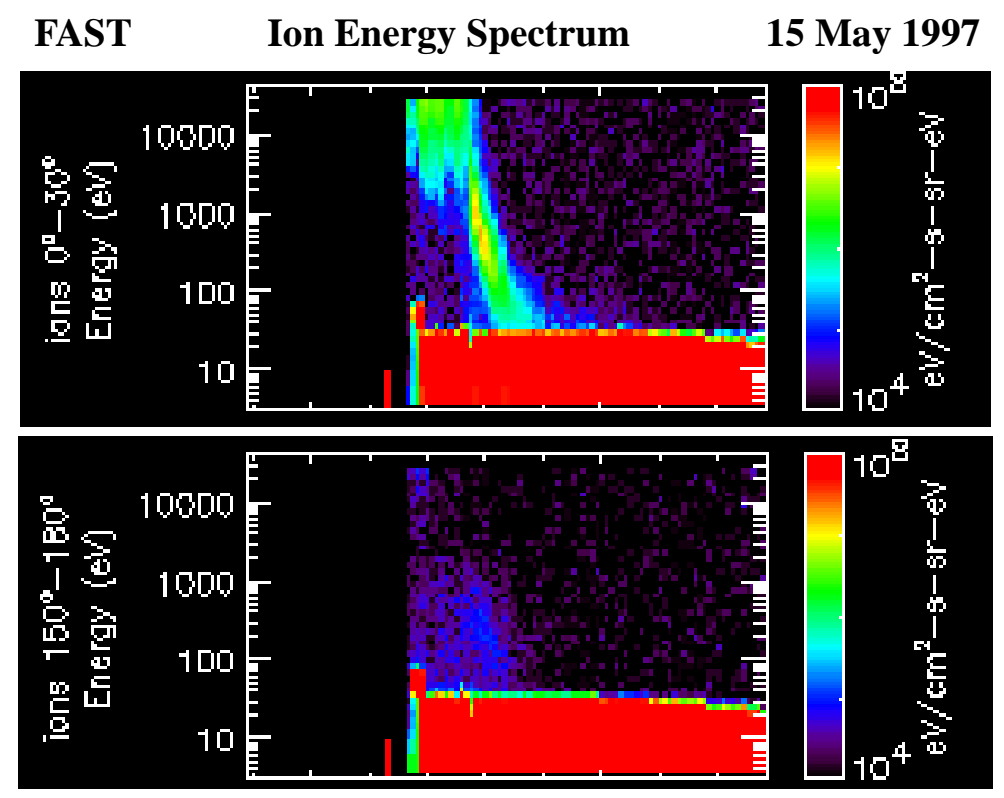

$\Uparrow$

UT $\quad 09: 40 \quad 09: 42 \quad 09: 44 \quad 09: 46$

LT $\quad 12: 55 \quad 13: 19 \quad 14: 10 \quad 16: 28$

$\begin{array}{lllll}\text { ILAT } & 55.4 & 62.5 & 68.4 & 72.5\end{array}$

$\begin{array}{llllll}\text { BLAT } & 61.5 & 69.5 & 77.0 & 82.5 & \left({ }^{\circ} \mathrm{N}\right)\end{array}$

$\begin{array}{llllll}\text { ALT } & 382 & 382 & 510 & 573 & (\mathrm{~km})\end{array}$

Fig. 5. Ion Energy Spectrum observed on the FAST satellite on 15 May 1997. The arrow below the picture indicates roughly the location of the equatorward edge of the ion dispersion region.

POLAR UV Image (vs. MLAT/MLT) at 09:52:00 UT on 15 May 1997

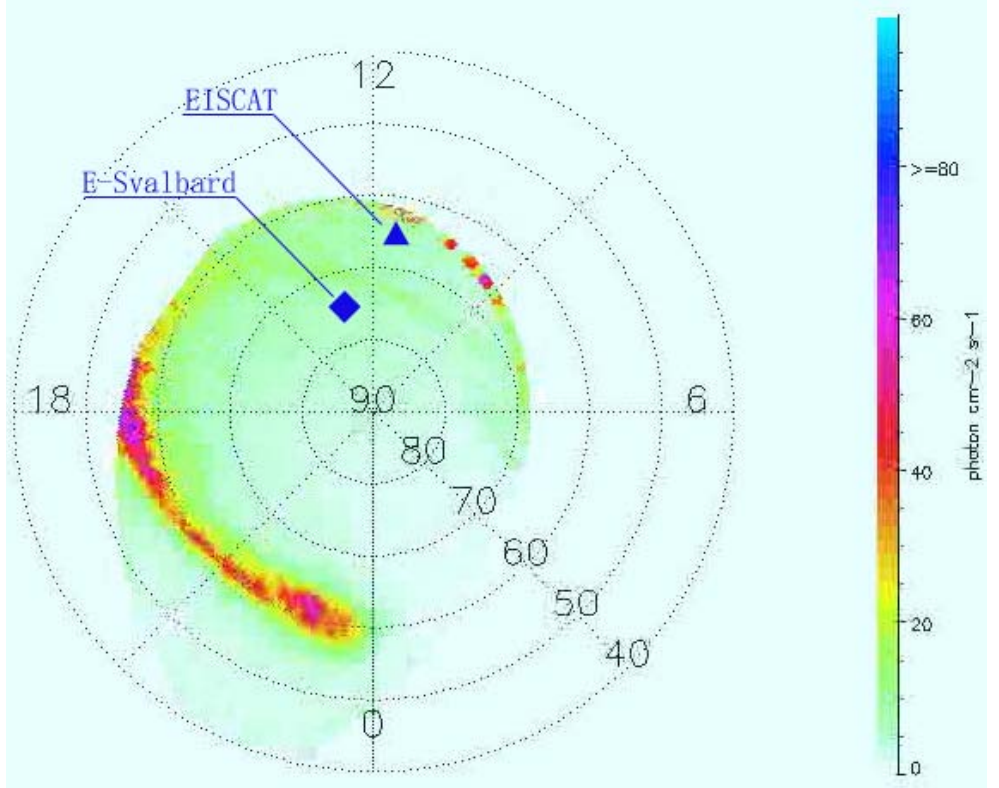

Fig. 6. UV Image of aurora taken on the POLAR satellite at 09:52 UT on 15 May 1997. The triangle indicates the location of EISCAT and the rectangle is for ESR. 


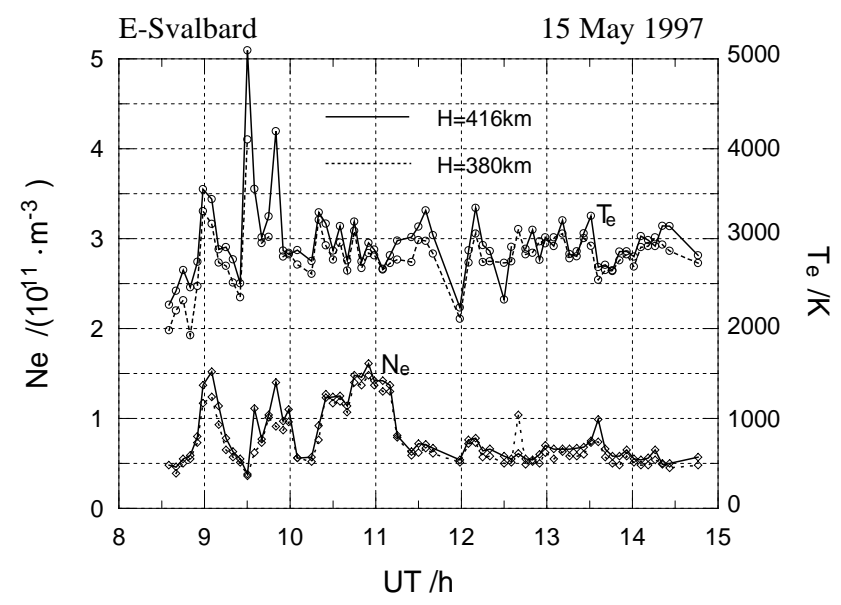

Fig. 7. Time variations of $N_{e}$ and $T_{e}$ at $380 \mathrm{~km}$ and $416 \mathrm{~km}$ height observed at Svalbard.

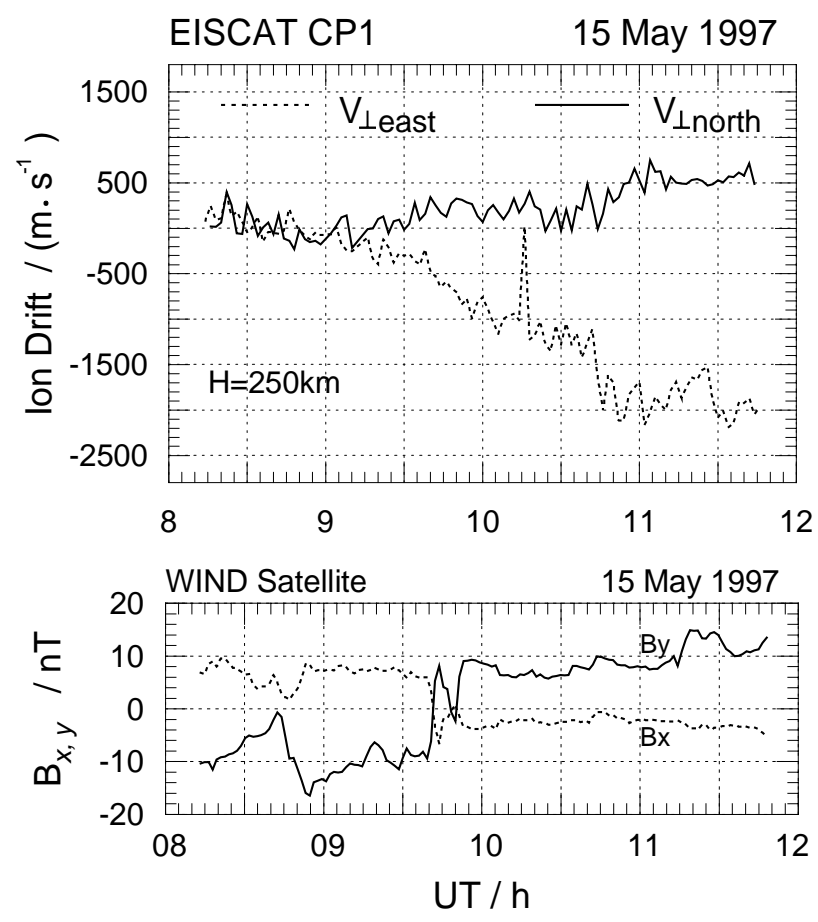

Fig. 8. Ion velocity perpendicular to the magnetic field observed at EISCAT. IMF $B_{x}$ and $B_{y}$, which affect the ion velocity, are shown at the bottom.

that a strong ionization enhancement appeared first over the EISCAT site around magnetic noon. The maximum percentage enhancement in electron density is as high as $80 \%$, with respect to a quiet reference level, and the positive storm phase lasted for $2 \mathrm{~h}$. About one hour later, a similar ionization enhancement was seen over ESR, with weaker enhancement and shorter duration. During the concerned time period, ion energy spectra measured on board FAST show clearly continuous energy-latitude dispersion when the satellite passed by over the EISCAT latitude. Consistently, POLAR UV images show strong dayside aurora extended down

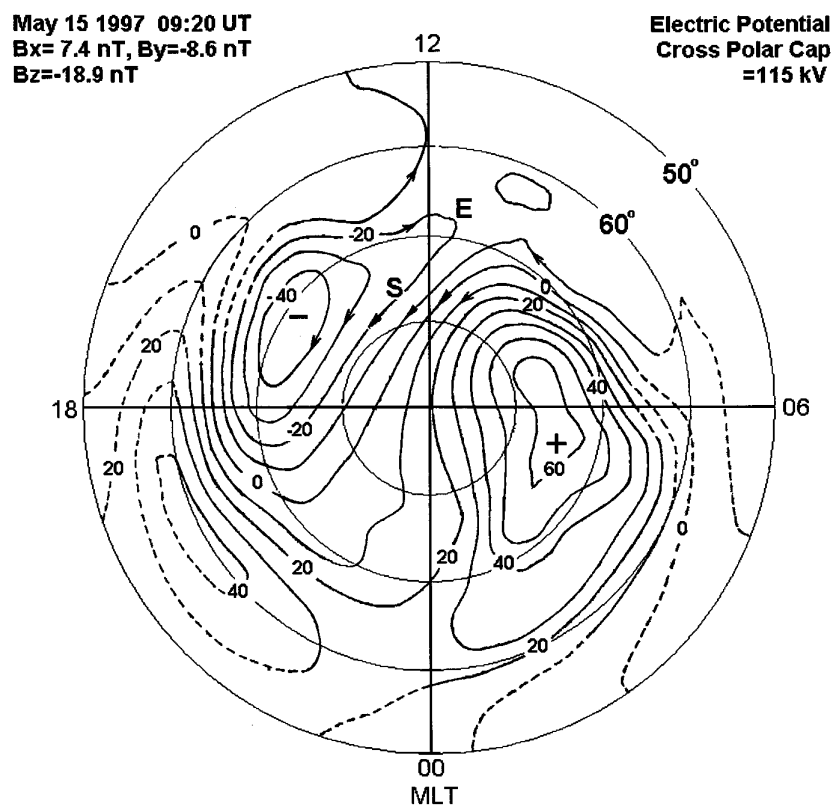

Fig. 9. Polar ionospheric convection pattern at 09:20 UT on 15 May 1997 produced by means of AMIE. Character E indicates EISCAT and S is for E-Svalbard.

to $62^{\circ} \mathrm{N}$ magnetic latitude. This implies that EISCAT was located under the polar cusp region and soft particles from the magnetosheath precipitated into the F-region ionosphere, leading to the positive storm effects over EISCAT. The cusp region was highly active and expanded greatly equatorwards due to magnetopause reconnection during long-lasting southward IMF. The coincident increase in electron temperature gives additional evidence for soft particle precipitations.

On the other hand, the ionization enhancement over ESR seems not to be caused by local particle precipitation, since no enhanced electron temperature was obviously observed. The polar ionospheric convection patterns produced by means of AMIE, as well as plasma convection velocity around the merging gap region under IMF $B_{y}$ conditions turning from dawnward $\left(B_{y}<0\right)$ to duskward $\left(B_{y}>0\right)$, suggests that the positive storm phase seen at ESR was probably a polar patch that originated from the active cusp region and travelled to the ESR site.

Acknowledgements. We are grateful to the director and staff of EISCAT for operating the facility and supplying the data. EISCAT is supported by Finland (SA), France (CNRS), Germany (MPG), Japan (NIPR), Norway (NAFN), Sweden (NFS), and the United Kingdom (PPARC). Thanks to all the relevant investigators of ISTP (WIND, FAST, POLAR spacecraft) for providing the data through CDAWeb. This study is granted by National Natural Science Foundation of China (No. 40074039) and China Ministry of Science and Technology for Major Basic Science Research (G2000 078407).

Topical Editor M. Lester thanks G. Millward and H. Rishbeth for their help in evaluating this paper. 


\section{References}

Cane, H. V., Richardson, I. G., and St Cyr, O. C.: The interplanetary events of January-May, 1997 as inferred from energetic particle data, and their relationship with solar events, Geophys. Res., Lett., Vol. 25, 2517-2520, 1998.

Danilov, A. D.: F2-region response to geomagnetic disturbances, J. Atmos. Solar-Terr. Physics, 63, 441-449, 2001.

Danilov, A. D. and Berlik, L. D.: Thermospheric composition and the positive phase of an ionospheric storm, Adv. Space Res., 12, 257-260, 1992.

Danilov, A. D., Morozova, L. D., Dachev, Ts., and Kutiev, I.: Positive phase of ionospheric storms and its connection with the dayside cusp, Adv. Space Res., 7, 81-88, 1987.

Fuller-Rowell, T. J., Codrescu, M. V., Moffett, R. J., and Quegan, S.:Response of the thermosphere and ionosphere to geomagnetic storms, J. Geophys. Res., 99, 3893-3914, 1994.

Fuller-Rowell, T. J., Rees, D., Tinsley, B. A., Rishbeth, H., and Rodger, A. S.: Modelling the response of the thermosphere and ionosphere to geomagnetic storms - effects of a mid-latitude heat source, Adv. Space Res., 10, 215-223, 1990.

Kennel, C. F.: The reconnecting Magnetosphere, Chapter 5 of "Convection and Substorm - Paradigms of Magnetospheric Phenomenology", Oxford University Press, New York, 1995.

Liu, H., Schlegel, K., and Ma, S. Y.: Combined ESR and EISCAT observations of the dayside polar cap and auroral oval during the May 15, 1997 storm, Ann. Geophys., 18, 1067-1072, 2000.

Lockwood, M. and Smith, S. E.: Low and middle altitude cusp particle signatures for general magnetopause reconnection rate variations. 1: Theory, J. Geophys. Res., 99, 8531-8553, 1994.

Lyons, L. R., Koskinen, H. E. J., Blake, J. B., Gaglis, I., Lemaire, J. F., Moldwin, M. B., Orsini, S., Thorne, R. M., and Wolfe, R. A.: Processes leading to plasma losses into the highlatitude atmosphere, Space Sci. Rev., 88, 85-135, 1999.

Makhailov, A. V., Skoblin, M. G., and Foerster, M.: Daytime F-2 layer positive storm effects at middle and lower latitude, Ann. Geophys., 13, 532-540, 1995.

Millward, G. H., Moffett, R. J., Balmforth, H. F., and Rodger, A. S.: Modeling the ionospheric effects of ion and electron precipitation in the cusp, J. Geophys. Res., 104, 24 603-24 612, 1999.

Namgaladze, A. A., Forster, M., and Yurik, R. Y.: Analysis of the positive ionospheric response to a moderate geomagnetic storm using a global numerical model, Ann. Geophys., 18, 461-477, 2000 .
Newell, P. T. and Meng, C.-I.: The cusp and the cleft/boundary layer: low-altitude identification and statistical local time variation, J. Geophys. Res., 93, 14 549-14 556, 1988.

Newell, P. T. and Meng, C.-I.: On quantifying the distinctions between the cusp and the cleft/LLBL, in: Electromagnetic Coupling in the Polar Cleft and cusp, NATO ASI Sec. C, Vol.278, eds: P. E. Sandholt and A. Egeland, p. 87, Kluwer Academic, Dordrecht, 1989.

Newell, P. T., Burke, W. J., Sanchez, E. R., Meng, C. I., Greenspan, M. E., and Clauer, C. R.,: The low-latitude boundary layer and the boundary plasma sheet at low altitude: pre-noon precipitation regions and convection reversal boundaries, J. Geophys. Res., 96, 21 013-21 023, 1991.

Prölss, G. W.: Ionospheric F-region storms, in: Handbook of atmospheric Electrodynamics, Vol. 2, ed.: H. Volland, 195-248, CRC press, Boca, Raton, FL, 1995.

Reiff, P. H., Hill, T. W., and Burch, J. L.: Solar wind plasma injection at the dayside magnetospheric cusp, J. Geophys. Res., 82, 479-491, 1977.

Richmond, A. D.: Assimilative Mapping of Ionospheric electrodynamics, Adv. Space Res., 12, 59-68, 1992.

Rishbeth, H., Fuller-Rowell, T. J., and Rodger, A. S.: F-layer storms and thermospheric composition, Special Committee on Solar Terrestrial Physics, Quadrennial International Solar-Terrestrial Physics Symposium, 6th, Toulouse, France, June 23-27, 1986, Physica Scripta, 36, 327-336, 1987.

Shelley, E. G., Sharp, R. D., and Johnson, R. G.: $\mathrm{He}^{++}$and $\mathrm{H}^{+}$ flux measurements in the dayside cusp: Estimates of convection electric field, J. Geophys. Res., 81, 2363-2370, 1976.

Smith, A. M., Pryse, S. E., and Kersley, L.: Polar patches observed by ESR and their possible origin in the cusp region, Annales Geophysicae, 18, 1043-1053, 2000.

Tsyganenko, N. A.: Effects of the solar wind conditions on the global magnetospheric configuration as deduced from data-based field models, in: Proceedings of the ICS-3 Conference on substorms, Versailles, France, May 12-17, 1996, ESA SP-389, 181$185,1996$.

Valladares, C. E., Basu, S., Buchau, J., and Frijs-Christensen, E.: Experimental evidence for the formation and entry of patches into the polar cap, Radio Sci., 29, 167-194, 1994.

Walker, L. K., Moen, J., Kersley, L., and Loretzen, D. A.: On the possible role of cusp/cleft precipitation in the formation of polarcap patches, Annales Geophysicae, 17, 1298-1305, 1999. 